regression analysis, the PD signals of the flexor tendons and collateral ligament were independent contributors to a diagnosis of dactylitis (Figure 1).

Conclusions: Development of active inflammation of enthesis organ determined by ultrasound is supposed to associate importantly with the judgment as dactylitis in patients with uSpA.

Disclosure of Interest: None declared

DOI: 10.1136/annrheumdis-2017-eular.3170

\section{AB1036 PREDICTIVE VALUE OF BASAL REACTANTS IN AN EARLY ARTHRITIS CLINIC. DOES ESR ELEVATION CRITERIA MAKE A DIFFERENCE?}

L. Mayordomo ${ }^{1}$, M.L. Velloso ${ }^{1}$, P. González-Moreno ${ }^{2}$, C. Gómez-Cano ${ }^{1}$,

A. Gutiérrez-Leonard ${ }^{3}$, J.L. Marenco ${ }^{1}{ }^{1}{ }^{1}$ Rheumatology Department, Hospital Universitario Valme; ${ }^{2}$ Rheumatology Department, HVM; ${ }^{3}$ Physioterapy, HVR, Sevilla, Spain

Background: The presence of high acute phase reactants may help the diagnosis and classification of patients with rheumatoid arthritis, specially in seronegative patients.

Objectives: Our objective was to establish if the presence of high basal reactants in early arthritis may help to establish the diagnosis of rheumatoid arthritis following criteria of ACR 1987 (which does not include positive reactants in diagnostic criteria). at 12 months of follow-up.

Methods: The presence of acute phase reactants at the baseline visit (elevated CRP and elevated ESR according to two different criteria) was studied in a population of 70 patients referred to the arthritis clinic with criteria for suspicion of early arthritis to meet at least one of the Following criteria: a) Swelling in 2 or more joints b) Pain in MCFs, MTFs and/or wrists c) Morning stiffness greater than 30 minutes ( ${ }^{*}$ SERAP study criteria), with $<12$ months of evolution of symptoms. None of the patients had previous diagnosis of rheumatoid arthritis or other inflammatory joint disease nor had previous treatment with steroids or DMARDs. The presence of high VSG $(\mathrm{mm} / \mathrm{h})$ was considered according to two criteria: a) ESR 1: VSG $>20$ or b) ESR 2 (criterion according to age and sex) (1): Age $\geq 50$ years $E S R>20$ in men and $E S R>30$ in women; Age $<50$ years of age, $E S R>15$ $\mathrm{mm} / \mathrm{h}$ in men and $>20$ in women.Statistics: Chi-square or Fisher test (for any value $<5)$, Odds ratio $(\mathrm{OR})$ calculation.

Results: 70 patientes, 45 women $(64,3 \%)$ x age $51,57 \pm 16,08$ y (18-85) were included, $x$ disease duration 3,47 meses $\pm 2,59(0,53-11.73), 48 / 70(68,5 \%)$ RF and ACPA negative. 49 patients meet ACR 1987 criteria, but 5 were finally classified in non-RA group because they meet criteria of other inflammatory chronic articular conditions (eg. psoriatic arthritis RA-like). 45/70 patients had high baseline CRP (64.3\%), ESR $138 / 70(54.3 \%)$ and ESR 2 35/70 (50\%). Basal $\mathrm{CRP}>5$ showed statistically significant differences for RA diagnosis (ACR 1987 criteria) $p=0.003, O R=4,64(1.62-13,24)$ but basal positive ESR 1 criteria did not $(p=0.122)$. Basal positive ESR2 showed significant differences for diagnosis of RA, with $\mathrm{p}=0.036, \mathrm{OR}=2,78(0,99-7,47)$. In the subgroup of seronegative patients, basal CRP could predict ACR 1987 RA diagnosis at 12 months follow-up $\mathrm{p}=0,019$, OR $4,2(1,23-14,36)$, but ESR (both ESR1 and ESR2) not $(\mathrm{p}=1,000)$. If the 5 patients ACR 1987 meeting criteria RA-like but diagnosed ot other inflammatory conditions were included, the results are similar but ESR2 reached a better confidence interval $p=0.036$, OR $3,63(1,20-10,94)$.

\begin{tabular}{|c|c|c|c|c|c|c|}
\hline \multicolumn{3}{|c|}{$\begin{array}{l}\text { RA ACR } 1987 \text { CRITERIA } \\
\text { A4.RT }\end{array}$} & \multirow{2}{*}{$\begin{array}{l}\text { RA YES } \\
\begin{array}{c}34 / 45(75,5 \%) \\
10 / 25(40 \%)\end{array}\end{array}$} & \multirow{2}{*}{$\begin{array}{r}\text { Punivariate } \\
0,003\end{array}$} & OR & IC $95 \%$ \\
\hline CRP & $\begin{array}{l}\text { YES } \\
\text { NO }\end{array}$ & & & & 4,64 & $(1,62-13,24)$ \\
\hline ESR1 & $\begin{array}{l}\text { YES } \\
\text { NO }\end{array}$ & & $\begin{array}{l}30 / 38(78,9 \%) \\
19 / 32(59,4 \%)\end{array}$ & $0,122 \mathrm{NS}$ & - & - \\
\hline ESR2 & $\begin{array}{l}\text { YES } \\
\text { NO }\end{array}$ & & $\begin{array}{l}26 / 35(74,3 \%) \\
18 / 35(51,4 \%)\end{array}$ & 0,048 & 2,78 & $(0,99-7,47)$ \\
\hline $\begin{array}{l}\text { CRP } \\
\text { seroneg }\end{array}$ & & $\begin{array}{r}\text { YES } \\
\text { NO }\end{array}$ & $\begin{array}{l}18 / 28(64,3 \%) \\
6 / 20(30 \%)\end{array}$ & 0,019 & 4,2 & $(1,23-14,36)$ \\
\hline
\end{tabular}

\begin{tabular}{|c|c|c|c|c|c|}
\hline \multicolumn{2}{|c|}{$\begin{array}{l}\text { ACR } 1987 \text { CRITERIA } \\
\text { (AR+AR-LIKE) } \\
\text { 49.RT }\end{array}$} & \multirow{2}{*}{$\begin{array}{l}\text { RA YES } \\
\begin{array}{l}37 / 45(82,2 \%) \\
12 / 25(48 \%)\end{array}\end{array}$} & \multirow{2}{*}{$\begin{array}{r}\text { P univariate } \\
0,006\end{array}$} & \multirow{2}{*}{$\begin{array}{r}\text { OR } \\
5,01\end{array}$} & \multirow{2}{*}{$\begin{array}{l}\text { IC } 95 \% \\
(1,67-14,98)\end{array}$} \\
\hline CRP & $\begin{array}{l}\text { YES } \\
\text { NO }\end{array}$ & & & & \\
\hline ESR1 & $\begin{array}{r}\text { YES } \\
\text { NO }\end{array}$ & $\begin{array}{l}30 / 38(78,9 \%) \\
19 / 32(59,4 \%)\end{array}$ & 0,116 NS & $\cdot$ & $\cdot$ \\
\hline ESR2 & $\begin{array}{l}\text { YES } \\
\text { NO }\end{array}$ & $\begin{array}{l}29 / 35(82,8 \%) \\
20 / 35(57,1 \%)\end{array}$ & 0,036 & 3,63 & $(1,20-10,94)$ \\
\hline
\end{tabular}

Conclusions: The presence of elevated basal $\mathrm{CRP}>5$ may be used as a factor that helps to predict the diagnosis of rheumatoid arthritis according to ACR 1987 criteria for RA. The baseline elevated ESR according to the sex and age criterion could be useful as a predictor factor for the diagnosis of rheumatoid arthritis, while the VSG criterion $>20$ in all patients does not demonstrate differences in the study between the two groups with final diagnosis AR and non-RA. In seronegative patientes, only CRP demostrated predictive value but ESR not.
References:

[1] Bottiger LE, Svedberg CA. Normal erythrocyte sedimentation rate and age. Br Med J 1967; 2:85-7.

Disclosure of Interest: None declared

DOI: 10.1136/annrheumdis-2017-eular.6659

\section{AB1037 INTEROBSERVER RELIABILITY OF KNEE OSTEOARTHRITIS LESIONS USING MUSCULOSKELETAL ULTRASOUND: DIFFERENCES BETWEEN STATIC VERSUS REAL TIME READING}

M.J. Audisio $^{1}$, A.M. Bertoli ${ }^{2}$, G.E. Py ${ }^{1} \cdot{ }^{1}$ Reumatología, DHEG; ${ }^{2}$ Reumatología, Instituto Strusberg, CORDOBA, Argentina

Background: Musculoskeletal ultrasound (MSU) is an imaging technique proved to be valid in several musculoskeletal conditions. In osteoarthritis (OA) it allows the identification of inflammation and structural damage. However, MSU is an operator dependent method and its widespread use has been hampered by questions related to the reliability of both, image acquisition and image interpretation.

Objectives: The objective of this study was 1) to evaluate the interobserver reliability of knee OA according to the definitions used by the OMERACT reliability exercise of inflammatory and structural abnormalities in patients with knee osteoarthritis using ultrasound and 2) to compare the interobserver reliability on previous collected images (static reading, thereafter) versus after the acquisition and interpretation of images in real time (real time reading, thereafter).

Methods: A reliability exercise based on the reading of US images was conducted by two experienced rheumatologists in MSU. A set of 59 images of both, normal and OA knee lesions were collected for the static reading. A set of 20 knees were scanned by each rheumatologist for the real time reading. Dichotomous and semi-quantitative scoring (0-3) was performed for the presence of damage on the condrosynovial margin, osteochondral margin and matrix of the throchlear cartilage, osteophytes at the lateral and medial femoral condyle and proximal tibia, medial and lateral meniscal extrusion and Baker's cyst. Interobserver reliability was calculated by the Cohen's kappa coefficient.

Results: Interobserver reliability scores for the static reading were good for cartilage damage, meniscal extrusion and Baker's cyst, while they were excellent for the presence of osteophytes. The scores for the real time reading were poor to moderate for cartilage damage, osteophytes and Baker's cyst and good for meniscal extrusion. These results are shown in Table 1.

Table 1. Interobserver $\mathrm{k}$ values for agreement of the static and real time reading of US abnormalities in knee osteoarthritis

\begin{tabular}{lcc}
\hline Lesion & $\begin{array}{c}\text { Static reading } \\
\kappa(\mathrm{SE})\end{array}$ & $\begin{array}{c}\text { Real time reading } \\
\kappa(\mathrm{SE})\end{array}$ \\
\hline Condrosynovial margin & $0,588(0,180)$ & $0,588(0,180)$ \\
Cartilage matrix & $0,732(0,118)$ & $0,317(0,143)$ \\
Osteochondral margin & $0,658(0,148)$ & $0,251(0,163)$ \\
Medial condyle osteophyte & $0,538(0,176)$ & $0,412(0,213)$ \\
Lateral condyle osteophyte & $0,792(0,194)$ & $0,385(0,228)$ \\
Medial tibial osteophyte & $0,865(0,129)$ & $0,490(0,96)$ \\
Lateral tibial osteophyte & $0,744(0,236)$ & $0,432(0,213)$ \\
Medial meniscal extrusion & $0,673(0,204)$ & $0,704(0,159)$ \\
Lateral meniscal extrusion & $0,633(0,234)$ & $0,573(0,185)$ \\
Baker's cyst & $0,714(0,256)$ & $0,490(0,960)$ \\
\hline
\end{tabular}

Conclusions: This exercise shows that the interobserver reliability of MSU for the detection of knee OA lesions is widely different depending on the type of reading (static versus real time). Although MSU seems to be reliable for the detection of knee OA lesions, caution needs to be taken in the interpretation of published data regarding the type of reading exercise performed.

References:

[1] Ann Rheum Dis 2016;75:842-846.

Disclosure of Interest: None declared

DOI: 10.1136/annrheumdis-2017-eular.3863

\section{AB1038 INFLUENCE OF AGE ON ENTHESIS IN TUNISIAN PEOPLE: AN ULTRASOUND STUDY}

K. Ben Abdelghani ${ }^{1}$, M. Chammakhi ${ }^{1}$, A. Fazaa ${ }^{1}$, S. Rejaibi ${ }^{2}$, S. Kassab ${ }^{1}$, S. Chekili ${ }^{1}$, A. Laatar ${ }^{1} .{ }^{1}$ Rheumatology, Hopital Mongi Slim; ${ }^{2}$ Epidemiology, Faculty of Medicine of Tunis, Tunis, Tunisia

Background: By aging, many changes occur in the different components of the locomotor system, leading to a pathological situation such as osteoarthritis or remaining totally asymptomatic.

Objectives: The aim of the current study was to compare,via ultrasound, the entheseal changes in two groups of people having different ages by calculating a modified Madrid sonography enthesitis index.

Methods: The study was conducted in the rheumatology department of Mongi Slim hospital in Tunisia, between June 2015 and December 2016, including 17 healthy subjects. We indentified two groups: (G1) 9 persons aged $>50$ years [51-68] and (G2) 8 persons aged $\leq 50$ years-old [37-50].

All the included persons underwent an enthesis ultrasound exploration (EsaoteMyLab 60 machine and a 13-18 MHz linear array transducer) by a rheumatogist 